\title{
Design and Validation of an Instrument for Evaluating the Social Capital of Faculty Members
}

\author{
Omid Pournik (iD ${ }^{1}$ and Leila Ghalichi (iD) ${ }^{2,}$ \\ ${ }^{1}$ Preventive Medicine and Public Health Research Center, Psychosocial Health Research Institute, Community and Family Medicine Department, School of Medicine, Iran \\ University of Medical Sciences, Tehran, Iran \\ ${ }^{2}$ Mental Health Research Center, Psychosocial Health Research Institute, Iran University of Medical Science, Tehran, Iran \\ "Corresponding author: Mental Health Research Center, Psychosocial Health Research Institute, Iran University of Medical Science, Shahid Hemmat Highway, 1449614535, \\ Tehran, Iran. Tel: +98-2166506862, Email: ghalichi.l@iums.ac.ir
}

Received 2020 July 13; Revised 2020 November 15; Accepted 2021 January 30.

\begin{abstract}
Background: Social capital refers to the degree and quality of connections in a certain community. The effect of social capital on productivity, absenteeism, and health of employees is reported by studies conducted in a variety of work environments.

Objectives: The current study aimed to, firstly, provide a better understanding of social capital conceptualized by the faculty members in Iran and, secondly, developing an instrument for its evaluation.

Methods: In this mixed-method study, initially, a search was performed to identify relevant literature for determinants of social capital at the workplace. Then, a semi-structured interview was performed with faculty members and experts. Afterward, a group of experts evaluated the obtained list of subscales and commented on the degree of relevance, importance, and grouping. Then, the questionnaire was developed based on the finalized list of determinants and expert opinions. Ten faculty members evaluated the questionnaire, comprised of 38 items, and after obtaining their approval, the questionnaire was completed by 32 faculty members from different universities.

Results: Identified determinants were categorized into five categories of ability and tendency to participate in workplace activities, trust in the workplace, social cohesion, access to information, and participation in groups and networks. Exploratory factor analysis revealed a structure corresponding to the theoretical dimensions previously extracted, and Cronbach's alpha ranged from 0.724 to 0.959 .

Conclusions: According to our findings, the social capital of faculty members can be evaluated by measuring ability and willingness to participate in workplace activities, trust and social cohesion in the workplace, access to workplace information, and membership in work-related groups and networks. We also provided a 38-item questionnaire for its evaluation, with acceptable internal consistency and conformity with the theoretical constructs.
\end{abstract}

Keywords: Social Capital, Workplace, Productivity

\section{Background}

Social capital is the set of information, rules, values, trust, and connections that enables coordination and cooperation in communities (1). During the past two decades, there has been considerable interest in social capital, and researchers have tried to attribute part of differences in health, well-being, productivity, crime, and other similar variables, at both individual and community level, to social capital (2). Social capital has two main aspects: an individual aspect that empowers a person to gain benefits, and a community aspect, which provides benefits for the community that cannot be owned by individuals (3). Social capital is composed of a structural participatory component that explains the nature and strength of participa- tion in the community and its networks. It is determined by the degree of personal or organizational connections the person is involved in. The cognitive perceived component of social capital defines the quality of these connections, which is measured by values, norms, attitudes, beliefs, and reciprocity in the targeted environment (1). There is growing evidence indicating the effect of social capital on health, burnout, sick leave, and presentism (4-8) at a variety of workplaces, as well as productivity, quality improvements, organizational efficiency, entrepreneurial ecosystem, innovation, and economic growth (9-11). In the business ecosystem, researchers have investigated social capital as an important social determinant of creativity, entrepreneurship, productivity, and similar concepts that af- 
fect the success and sustainability of organizations $(9,10)$.

In the present competitive sphere, universities are expected to act as an important source of knowledge creation and innovation for countries (12). In an effort toward a knowledge-based economy, universities are assuming leadership roles toward entrepreneurial society (13), which is an expansion to the current roles of universities, from sources of knowledge creation and human capital development to entrepreneurial organizations (14). Literature highlights the role of social capital as a facilitator of university-industry collaboration, which plays a determining role in the creation and maintaining connections between the two cooperating organizations, which is affected by characteristics of the firm, as well as the knowledge-creating organization (15). For faculty members participating in innovation-related activities of the universities, the acquired social capital is an important determinant, both at the individual and collective level (16).

In line with the abovementioned changes in the university roles, faculty members are also facing increased expectations and responsibilities. They are faced with constantly changing duties and expectations, even sometimes they are required to assume new unprecedented roles (17). The abovementioned transitions in the work environment have resulted in noticeable changes in the personal approaches and value systems. Personal and organizational commitments and interpersonal connections have been modified in this rapidly changing environment. Universities may provide mentoring and coaching by providing social capital and knowledge support. (14) Thus, before planning any intervention to improve the education system, work condition, productivity, or innovation, we need to have a better understanding of the construct of social capital as an important determinant of acceptance and success of the changes.

\section{Objectives}

Considering the new expectations from faculty members in today's universities and the role of workplace social capital in productivity, innovation, and entrepreneurship, university leaders are in search of strategies to improve the capacity of their organizations in innovation leadership and paving the way for achieving economic development mission of universities. Such approaches require a more detailed understanding of social capital construct and determinants. This study aimed to, firstly, identify different aspects of social capital through a mixed-method study and, secondly, developing a psychometrically valid context-specific tool to evaluate the social capital of faculty members in the academic environment.

\section{Methods}

This is a mixed-method study including both quantitative and qualitative study designs. The ethics committee of the Iran University of Medical Sciences (IR.IUMS.REC 1396.31040) approved the study. It includes a rapid review to identify the relevant literature and variables, a qualitative section to clarify the experiences, and a quantitative section to evaluate the psychometric properties of the proposed questionnaire.

As the first step of this study, a thorough literature search was performed in databases, books, websites, and other academic resources for determining factors of social capital at the workplace. We searched Web of Science, Scopus, and Medline databases to identify relevant variables with the keywords of "social capital" and "workplace", between 2008 and 2018. We included all types of articles (original, reviews, case studies, letters, editorials). Besides, the reference list of the selected articles was hand-searched to increase the comprehensiveness of the search. The article would be included if it named a variable as part of the causal network of social capital, based on empirical evidence or theoretical basis. Two reviewers screened the articles separately, and any article selected by either of the reviewers would be included in the data extraction phase. We extracted determinants of social capital in a variety of work environments (hospitals and health care facilities, industries, schools, and other educational institutes, etc.), as well as neighborhoods and communities.

For the qualitative section of the study, we performed a nonprobability purposive sampling. The two researchers performed in-deep interviews with faculty members who were selected based on the diversity of the position, field of education, and personal experiences. They were influential people with a renowned academic position with a history of mentoring younger academic members, or those in charge of evaluation and conflict management in faculties of the universities, or members with a background in human resources management. At the beginning of the interview, the concept was briefly explained to the interviewee, and their consent was sought both for participation in the research and recording the session. An assistant was presented in the sessions to help with transcription in cases that the interviewee did not wish the session to be recorded. We applied a semi-structured questionnaire based on the findings of the previous step. It included questions on how they conceptualize their social capital within and outside the academic environment, how much they feel that they contribute to the present level of social capital in their department and how they do that. Then, we asked them about what they believe affects or is affected 
by social capital in their department, if these items have changed in recent years, and why do they believe these changes are happening, and how do they expect it to affect the social capital of their colleagues. We mentioned a list of variables extracted from the previous section, and we asked if they considered them to play a role in their department and if it was changing over time. In the end, we asked them if there were any neglected aspects and if they knew of anyone who could give us a better insight into the topic. We interviewed new participants until no more themes emerged and saturation was achieved. The interviews continued until saturation occurred after 12 interviews.

In addition, we held four focus group discussions to extract the viewpoints of a larger group of academicians on the topic. In each session, we tried to gather a diverse group of academicians (between 4 to 8 participants, with a total of 27 people) and to encourage them to talk about their experiences and discuss their viewpoints. The sessions were audiotaped and transcribed. Thematic analysis was applied, and the transcripts were later analyzed and coded to extract the domains and themes. Conventional content analysis was performed for qualitative data analysis. Two researchers coded the transcripts independently. The codes were later reviewed and categorized until the final structure evolved.

In the next step, themes were reviewed, and their correlation with the domains extracted from the literature was demonstrated. A primary list of scales and sub-scales of probable determinants was prepared, and expert opinion was requested on their degree of relevance, importance, and grouping by email. The responses were collected and analyzed. There were some discrepancies between the opinions of some experts, and we needed to hold another session with them to discuss the issues further. Based on the final set of revised domains, the preliminary questionnaire was sent to the experts for their final approval as the content validity measure. Then, a 38-item questionnaire was finalized, and 6 faculty members evaluated its face validity and comprehensiveness. Minor changes were made according to their comments. The revised questionnaire was completed by 32 faculty members from different medical universities in Iran who were selected using a convenient sampling technique and accepted to help us in developing the questionnaire. At the final step, for determining the construct validity of the proposed questionnaire, principal components analysis was performed to compare the questionnaire structure with the theoretical basis derived. Cronbach's alpha was calculated as a measure of internal validity. We administered SPSS version 25 for data analysis.

\section{Results}

Our rapid review revealed a body of literature on variables associated with social capital, although frequently, the associations were reciprocal. Researchers had also paid attention to interacting variables, both in empirical studies and theoretical models. In many instances, the structure of workplace social capital would be similar to general social capital, with different emphasis on some aspects. Access to information and connection with influential people are examples of such variables. Demographic variables and personal background (place and field of education, work tenure, previous organizations) were considered to affect the type of inter-personal connections and level of social capital. On the organization side, the corporate governance in terms of transparency in roles, goals, and guidelines; and providing a shared vision for the employees, as well as ethical conduct of the organization, were considered important. Social climate, mutual respect, collaboration, and efficient formal and informal communication also played a role. Trust was a central topic, with both particularized and generalized trust being evaluated. Supervisor and coworker support, information and idea sharing, cooperative environment, reciprocity, autonomy, institutional commitment, and sense of equity were all part of the discussed literature. Diversity was another frequently investigated topic, which could affect social capital in different aspects. The researchers also investigated the social capital association with productivity, health, innovation, job satisfaction, financial achievements, and entrepreneurship.

We interviewed 12 senior or influential members of the university (eight men and four women). The youngest and oldest interviewees were 45 and 71 years old, respectively. We also held 4 focus groups with participants ranging from 35 to 61 years old, who were professors or assistant and associate professors. We observed two different approaches from the faculty members in both interviews and focus groups. The first group expressed their concerns about declined social capital due to new people, methods, and policies. The second group aimed at exploring new areas of social capital.

The interviewees highlighted the importance of official groups and teamwork in making long-lasting and useful connections and further transformation of these groups into unofficial networks for information sharing and influencing the work environment. "We have been friends since we worked together as university managers many years ago, and when something happens, we act as a team." When asked about the changes he expects to see in future years, he added, "Today we are senior members in 
different departments... We try our best, and we use our resources to help our university work successfully. We want to help younger people; we will be leaving here eventually, and it would be a relief to think the new generation care for the university and department just as we did", highlighting his sense of belonging and attachment to the university.

Other important aspects, which were highlighted in many of the interviews and focus group sessions, were the presence of conflicts within departments and the role of unofficial groups, which can affect the process of nomination and selection for different positions, and access to funds and grants and other available resources. It was expressed that such groups are created based on mutual interests, presence of influential people, concerns about social support in case of injustice, and indifference of other members towards group interests; and belonging to such groups can make the workplace more pleasant and productive. "... So they try to keep themselves (the new members) out of existing networks and groups. These brilliant new faculty members no more accept to be a follower. They have ideas and connections of their own. They provide new resources for the departments. Students admire them, managers trust them ...These conflicts weaken the ties between members of a department and do not provide the opportunity for the new members to develop a sense of belonging. Instead, they strengthen their ties elsewhere, so the dynamics of the connections change in the organization." Another key person mentioned the changes in source and type of social capital.

Access to information was another common theme in the interviews. "If you are the last person to know about the events, whether a change in the office, a prize nomination, a grant announcement, or even a member getting married, you know that you are not a member," an interviewee mentioned.

After theme extraction, we had eight categories: Participation and membership, Trust, Unity and cooperation, Belonging and support, University policies and trends, Effect, Personal characteristics, and Access to information. The codes and themes are presented in Table 1.

The abovementioned situation can affect the trust domain both directly and indirectly. Eventually, those who are not members of influential groups and have less access to information resources in the academic environment lose their sense of trust towards university officials and processes. "This is a game of their own. The criteria and the decisions are made based on the group they belong to. No evidence-based decision-making, as they claim. Unless diverse people have a sound in university offices, this is not going to change." A young faculty member men- tions. Meanwhile, it was generally mentioned that the presence of influential members of academia who are respected by different groups in the university acts as an important source of trust and solidarity and improves general sentiments towards officials. "She acts as an advocate for everyone, helping us reach our voice to the officials, sometimes solving conflicts over a cup of tea in her office." Alternatively, in another case, it was mentioned, "People listen to him. He uses his resources to smooth the situations and conflicts. At least he listens to people and offers wise comments, especially to young colleagues".

The interviewees mentioned other situations in which social capital and its determinants could affect work conditions. For instance, sanctions affect the availability of laboratory materials and instruments. In such situations, those with better interpersonal connections can overcome such shortcomings more easily, both for their own research projects and those of their network. For instance, access to unused materials in the labs, the collective use of kits (to reduce the discards and wastes), and other similar collective activities can happen within groups and networks and affect the productivity of the members.

In light of recent floods and earthquakes in the country, frequent references are made to the collective action of academic members in these national catastrophes, indicating new connections and familiarizations between faculties during these mutual activities that both showed the sense of belonging to the reference department, school or university, and at the same time improving such emotions.

Based on these items, a 38-item questionnaire with five general domains was developed: 1- Ability and willingness to participate in workplace activities (11 questions); 2 Trust in the workplace (6 items); 3 - Social cohesion in the workplace (6 items); 4- Access to workplace information (3 items); 5-Membership in groups and networks (12 items).

For a better understanding, 12 items on general trust (change in trust in the past 5 years and trust to reference groups) were added to the questionnaire. The items were generally scored from one to five, and the sum of the scores was calculated for each domain. Three items (the underlying reason for conflict, 5-year change in the workplace trust, and the most important group) were not used in calculating the scores and aimed for a complementary analysis.

The final questionnaire was completed by 32 faculty members from different medical universities of Iran. The participant's age ranged from 33 to 58, and 19 of them were male. The Cronbach's alpha for these domains ranged from 0.724 to 0.959 (Table 2).

For further evaluation of the construct of the questionnaire, we analyzed the results by principal component 


\begin{tabular}{|c|c|}
\hline Categories & Codes \\
\hline \multirow[t]{5}{*}{ Participation and membership } & Ability to participate \\
\hline & Tendency to participate \\
\hline & Acceptance in an official workgroup \\
\hline & Acceptance in unofficial groups and connections \\
\hline & Acceptance in other organizations \\
\hline \multirow[t]{3}{*}{ Trust } & Officials and managers \\
\hline & Colleagues \\
\hline & Information sources \\
\hline \multirow[t]{5}{*}{ Unity and cooperation } & Common vision \\
\hline & Cooperating for organizational goals \\
\hline & Common scientific interests and activities \\
\hline & Common organizational interests and activities \\
\hline & Common social interests and activities \\
\hline \multirow[t]{3}{*}{ Belonging and support } & From team members \\
\hline & From influential people in the workplace \\
\hline & From organization and officials \\
\hline \multirow[t]{4}{*}{ University policies and trends } & Conflict management \\
\hline & Justice \\
\hline & Transparency \\
\hline & Diversity tolerance and demanding \\
\hline \multirow[t]{2}{*}{ Effect } & Influencing the decisions in the department \\
\hline & Influencing on university policies \\
\hline \multirow[t]{4}{*}{ Personal characteristics } & Personality and traits \\
\hline & Background \\
\hline & Personal connections \\
\hline & Cyberspace connections and activities \\
\hline \multirow[t]{3}{*}{ Access to information } & Anticipated changes in strategies or rules \\
\hline & Events and opportunities outside the university (ministry of health, granting agencies, etc.) \\
\hline & Unofficial events and connections \\
\hline
\end{tabular}

Table 2. Cronbach's Alpha for the Domains of Faculty Members' Social Capital Questionnaire

\begin{tabular}{lcc}
\hline Domain & Number of Items & Cronbach's Alpha \\
\hline Ability and willingness to participate in workplace activities & 11 \\
Trust in workplace & 6.959 \\
\hline Social cohesion in the workplace & 6.849 \\
Access to workplace information & 6 \\
\hline Membership in groups and networks & 3 & 0.724 \\
\hline
\end{tabular}


analysis. Bartlett's Test of Sphericity was significant (P value $<0.01$ ), a criterion of good factorability. The test revealed nine empirical factors. Two factors perfectly corresponded to "social cohesion in the workplace" and "trust". Two factors mutually corresponded to the "Ability and willingness to participate in workplace activities" domain. The items regarding "membership in groups and networks" were also aggregated in two factors. The item regarding "pursuing workplace news and events" which we had previously categorized in the "access to workplace information" domain, was better placed in the "Social cohesion in workplace" domain. Overall, factor analysis showed acceptable similarity with the theoretical constructs.

\section{Discussion}

Our literature review revealed that the determinants of social capital at the workplace were similar to those of general social capital, while the usage pattern of resources is different. In the workplace, access to information and knowledge resources seemed to play a more important role than it does in the general population. Both literature review and expert meetings highlighted that access to information and connection with information resources is a more critical determinant in the workplace compared to everyday life. Receiving information about ongoing programs, plans, and directions, changes in the organizational strategies, as well as personal connections with key informants were highly effective on the level of social capital one experiences in an academic environment.

Many researchers believe that workplace social capital cannot be appropriately measured by questionnaires designed for communities and neighborhoods (18). Constructs and concepts of social capital have been evaluated in firms, health care professions, public services, schools, and many other settings. Despite similarities in construct and concepts, there are critically important aspects in the workplace social capital. A concept analysis study among nurses defined attributes of workplace social capital as networks of social connections and shared assets and ways of knowing and being at the workplace that were formed through communication, trust, and positive leadership at work (19). To measure social capital in the workplace, a few questionnaires have been developed. Trust, sense of community, and organizational justice are important themes frequently evaluated in these questionnaires (20-22), while respect, network status, reciprocity, shared language, cognitive common ground, and shared narrative also received attention (23).

Meanwhile, a growing body of literature exists on the effect of social capital in academia-related activities such as knowledge creation and sharing as well as entrepreneurial activities that suggest the need for a more focused evaluation of social capital in academic workplaces. In recent decades, the increased inclusion of women and immigrant professionals with heterogeneous academic and educational backgrounds has formed a new, diverse academic environment. Creating a more diverse research team has been used in some organizations as a policy to improve research output (24). Such diversity, along with other characteristics, can result in an augmented bridging social capital and acts as a mean for knowledge production and sharing as well as discovering new methods and approaches in complicated situations. In other words, it is the social capital and not the diversity that plays a mediating role in knowledge transfer between heterogeneous groups. As expected, this process can be modified by the socio-cognitive status of the organization (25).

Our results highlight the importance of academic inter-personal connections in the formation of social capital and, consequently, the academic output. The degree of influence on peers and colleagues, which might be the result of scientific mastery or other types of superiority, as well as executive influence and power in the organization, affect the social capital. Consequently, there were critics of the traditional methods of academic evaluation that do not take into account the role a faculty member plays in the network and its consequences. To improve long-term standing and outcome, along with research and publication activities, younger researchers generally try to increase their social capital by network building as a way to compensate for other aspects. This has resulted in higher scores in groups and network domain for younger researchers (26). Such efforts can modify the general characteristics of the network in the workplace; and affect the dynamics of social capital in the organization. In this context, part of what is identified as groups and network domain is the consciously augmented inter-personal and reciprocal interactions. It should be emphasized that interventions targeting social capital are among the most context-specific ones, and their success is highly affected by frames and boundaries in the field (27). Nevertheless, any evaluation on the effect of social capital interventions should adopt a multilevel perspective and consider differences present in the subgroups (8). The faculty members contribute to the scientific output of the organization both directly by their research products and indirectly through their role in the social capital dimensions, which cannot be captured by traditional scientometrics methods (26).

In this study, we evaluated both general trust and particularized trust. It is demonstrated in previous studies 
that the particularized trust (trust in known others) is more strongly associated with self-rated health. Although, some researchers believe that the effects of trust and social networks on health are dependent on one another (28). Social capital and its dimensions are also shown to be associated with happiness in faculty members, which is believed to affect burnout and absenteeism at the workplace in a study from Iran (29). For accomplishing their training responsibilities, faculty members need to develop teachingfocused social networks, which is highly affected by teaching experience tenure, the time needed for teaching material preparation, discipline, and characteristics of the organization, such as organizational support. Both faculty members and the respective organization should make investments to achieve these benefits (30). For instance, access to research funding at the early stages of the career highly affects the research output of the researchers, which might, in turn, be affected by organizational characteristics (31). In addition, the universities tend to span the boundaries and improve international partnerships as a mechanism to reinforce cohesion and commitment between stakeholders through facilitated knowledge and resource transmission, which can result in a more renowned organization and improved social capital (32).

We performed this study in the context of medical universities in Iran, which might affect the generalizability of our findings. The selection was due to the complexity of this setting resulting from their simultaneous responsibility in education and research and health service, as well as increased attention of policymakers on medical research and knowledge creation in the recent decade. Nevertheless, to improve the validity of our findings, we tried to triangulate the findings based on the convergence of the concepts from participants with different backgrounds, as well as literature from diverse settings.

Faculty members' social capital can be an important determinant of personal and organizational scientific output in the competitive atmosphere of our era. Understanding this concept can be critical for policymakers who aim to improve the work condition in universities and achieve higher levels of knowledge production and scientific authority. According to our findings, this concept can be evaluated by measuring ability and willingness to participate in workplace activities, trust and social cohesion in the workplace, access to workplace information, and membership in work-related groups and networks. We also provided a 38-item questionnaire for evaluating faculty members' social capital, with acceptable internal consistency and conformity with the theoretical constructs. The effectiveness of policymaking in medical universities could be improved with a better understanding of the current sta- tus of social capital. These assessments can be useful for evaluating the policies and interventions.

\section{Acknowledgments}

We appreciate all faculty members from different medical universities who supported us by contributing to different parts of this study.

\section{Footnotes}

Authors' Contribution: O.P. contributed to study acquisition of data, analysis and interpretation of data, critical revision of the manuscript and statistical analysis; L.G. contributed to study concept and design, acquisition of data, analysis and interpretation of data, drafting of the manuscript and statistical analysis.

Conflict of Interests: The authors have no conflict of interest to declare.

Ethical Approval: The ethics committee of the Iran University of Medical Sciences (IR.IUMS.REC 1396.31040) approved the study.

Funding/Support: This study was supported by the Iran University of Medical Sciences (code: 96-02-121-31040).

\section{References}

1. Flores EC, Fuhr DC, Bayer AM, Lescano AG, Thorogood N, Simms V. Mental health impact of social capital interventions: a systematic review. Soc Psychiatry Psychiatr Epidemiol. 2018;53(2):107-19. doi: 10.1007/s00127-017-1469-7. [PubMed: 29234826]. [PubMed Central: PMC6040224].

2. Rodgers J, Valuev AV, Hswen Y, Subramanian SV. Social capital and physical health: An updated review of the literature for 2007-2018. Soc Sci Med. 2019;236:112360. doi: 10.1016/j.socscimed.2019.112360. [PubMed: 31352315].

3. Martín-Alcázar F, Ruiz-Martinez M, Sánchez-Gardey G. Social capital and academic research performance: A conceptual model proposal. Int J Bus Adm. 2019;10(2):22. doi: 10.5430/ijba.v10n2p22.

4. Ghalichi L, Nedjat S, Majdzadeh R, Hoseini M, Pournik O, Mohammad K. Determinants of self-rated health in Tehran, from individual characteristics towards community-level attributes. Arch Iran Med. 2015;18(5):266-71.

5. Eliacin J, Flanagan M, Monroe-DeVita M, Wasmuth S, Salyers MP, Rollins AL. Social capital and burnout among mental healthcare providers. J Ment Health. 2018;27(5):388-94. doi: 10.1080/09638237.2017.1417570. [PubMed: 29307259].

6. Torok E, Clark AJ, Jensen JH, Lange T, Bonde JP, Bjorner JB, et al. Work-unit social capital and long-term sickness absence: a prospective cohort study of 32053 hospital employees. Occup Environ Med. 2018;75(9):623-9. doi: 10.1136/oemed-2017-104954. [PubMed: 29875292].

7. Zhu Y, Gao J, Wang J, Yu D, Nie X, Dai J, et al. Association Between Workplace Social Capital and Absolute Presenteeism: A Multilevel Study in a Chinese Context. J Occup Environ Med. 2018;60(10):e543-7. doi: 10.1097/JOM.0000000000001421. [PubMed: 30095589]. 
8. Villalonga-Olives E, Wind TR, Kawachi I. Social capital interventions in public health: A systematic review. Soc Sci Med.2018;212:203-18. doi: 10.1016/j.socscimed.2018.07.022. [PubMed:30048843]

9. Kaasa A. Social capital, institutional quality and productivity: Evidence from european regions. Econ Sociol. 2016;9(4):11-26. doi: 10.14254/2071-789x.2016/9-4/1.

10. Theodoraki C, Messeghem K, Rice MP. A social capital approach to the development of sustainable entrepreneurial ecosystems: an explorative study. Small Bus Econ. 2017;51(1):153-70. doi: 10.1007/s11187-0179924-0.

11. Thompson M. Social capital, innovation and economic growth. J Behav Exp Econ. 2018;73:46-52. doi: 10.1016/j.socec.2018.01.005.

12. Tseng F, Huang M, Chen D. Factors of university-industry collaboration affecting university innovation performance. J Tech Tran. 2018;45(2):560-77. doi:10.1007/s10961-018-9656-6.

13. Hayter CS. A trajectory of early-stage spinoff success: the role of knowledge intermediaries within an entrepreneurial university ecosystem. Small Bus Econ. 2016;47(3):633-56. doi: 10.1007/s11187-0169756-3.

14. Klofsten M, Fayolle A, Guerrero M, Mian S, Urbano D, Wright M. The entrepreneurial university as driver for economic growth and social change - Key strategic challenges. Technol Forecast Soc Change. 2019;141:149-58. doi: 10.1016/j.techfore.2018.12.004.

15. Steinmo M, Rasmussen E. The interplay of cognitive and relational social capital dimensions in university-industry collaboration: Overcoming the experience barrier. Research Policy. 2018;47(10):1964-74. doi:10.1016/j.respol.2018.07.004.

16. Redondo M, Camarero C. Social Capital in University Business Incubators: dimensions, antecedents and outcomes. Int Entrepreneurship ManagJ. 2018;15(2):599-624. doi:10.1007/s11365-018-0494-7.

17. Foo HY, Turner JJ. Entrepreneurial learning'-the role of university led business incubators and mentors in equipping graduates with the necessary skills set for Industry 4.0. Int J Educ. 2019;4()(30):283-98.

18. Firouzbakht M, Tirgar A, Ebadi A, Sharif Nia H, Oksanen T, Kouvonen A, et al. Psychometric properties of persian version of the short-form workplace social capital questionnaire for female health workers. Int J Occup Environ Med. 2018;9(4):184-93. doi: 10.15171/ijoem.2018.1264. [PubMed: 30325359]. [PubMed Central: PMC6466993].

19. Read EA. Workplace social capital in nursing: an evolutionary concept analysis. J Adv Nurs. 2014;70(5):997-1007. doi: 10.1111/jan.12251. [PubMed: 24103033].

20. Berthelsen $\mathrm{H}$, Westerlund $\mathrm{H}$, Pejtersen JH, Hadzibajramovic E. Construct validity of a global scale for Workplace Social Capital based on COPSOQ III. PLoS One. 2019;14(8). e0221893. doi: 10.1371/journal.pone.0221893. [PubMed: 31465500]. [PubMed Central: PMC6715184]
21. Kouvonen A, Kivimaki M, Vahtera J, Oksanen T, Elovainio M, Cox T, et al. Psychometric evaluation of a short measure of social capital at work BMC Public Health. 2006;6:251. doi: 10.1186/1471-2458-6-251. [PubMed 17038200]. [PubMed Central: PMC1618843].

22. Pournik O, Ghalichi L, TehraniYazdi A, Tabatabaee SM, Ghaffari M, Vingard E. Measuring psychosocial exposures: validation of the Persian of the copenhagen psychosocial questionnaire (COPSOQ). Med J Islam Repub Iran. 2015;29:221. [PubMed: 26478879]. [PubMed Central: PMC4606950].

23. Read EA, Laschinger HK, Wong CA, Fida R, Finegan J. Development and validation of a workplace social capital questionnaire for nurses (WSCQ-N). 27th international Nursing Research Congress. Cape Town, South Africa. Sigma Theta Tau international, the Honor Society of Nursing; 2016.

24. Ku M. Similarity-dissimilarity and social capital in research knowledge networks: explaining knowledge sharing in academic institutions. Knowl Manag Res Pract. 2019;17(3):264-75. doi: 10.1080/14778238.2019.1595986.

25. Tsai F-S. Composite diversity, social capital, and group knowledge sharing: A case narration. Knowl Manag Res Pract. 2017;3(4):218-28. doi: 10.1057/palgrave.kmrp.8500075.

26. Lutz C, Hoffmann CP. Making academic social capital visible. Soc Sci Comput Rev. 2017;36(5):632-43. doi: 10.1177/0894439317721181.

27. Shiell A, Hawe P, Kavanagh S. Evidence suggests a need to rethink social capital and social capital interventions. Soc Sci Med 2020;257:111930. doi: 10.1016/j.socscimed.2018.09.006. [PubMed: 30219489].

28. Glanville JL, Story WT. Social capital and self-rated health: Clarifying the role of trust. Soc Sci Res. 2018;71:98-108. doi: 10.1016/j.ssresearch.2018.01.002. [PubMed: 29514763].

29. Hosseinbor MO, Nabizadeh R. Examining the relationship between social capital and happiness among faculty members of Urmia University of Medical Sciences. J Adv Pharm Res. 2019;9(S2).

30. Benbow RJ, Lee $\mathrm{C}$. Teaching-focused social networks among college faculty: exploring conditions for the development of social capital. Higher Education. 2018;78(1):67-89. doi:10.1007/s10734-018-0331-5.

31. Blanchard RD, Kleppel R, Bianchi DW. The Impact of an Institutional Grant Program on the Economic, Social, and Cultural Capital of Women Researchers. JWomens Health (Larchmt). 2019;28(12):1698-704 doi: 10.1089/jwh.2018.7642. [PubMed: 31259641]. [PubMed Central PMC6998046].

32. Bordogna CM. The effects of boundary spanning on the development of social capital between faculty members operating transnational higher education partnerships. Stud High Educ. 2017;44(2):217-29. doi: 10.1080/03075079.2017.1349742. 